\title{
PERANAN GURU DALAM PENGGUNAAN MEDIA PEMBELAJARAN BERBASIS INFORMATION AND COMMUNICATION TECHNOLOGY (ICT) DI SDN RRI CISALAK
}

\author{
Iis Dewi Lestari \\ Program Studi Informatika, Universitas Indraprasta PGRI \\ Email: iisdewilestari@unindra.ac.id
}

\begin{abstract}
Abstrak
Dalam proses pembelajaran hal yang terpenting adalah guru dan media pembelajaran. Dengan penggunaan dan pemilihan media pembelajaran yang tepat dilakukan oleh seorang guru tentunya akan berpengaruh pada proses dan hasil dari pembelajaran yang dilakukan. Media pembelajaran berbasis Teknologi Informasi dan Komunikasi menjadi hal yang sangat penting dalam perkembangan dunia pendidikan. Teknologi Informasi dan Komunikasi (TIK) merupakan suatu program, untuk alat bantu, manipulasi dan menyampaikan informasi. Proses pembelajaran di kelas menjadi lebih mudah dalam mencari informasi, manipulasi, pengelolaan dan transfer ilmu. Dengan media pembelajaran berbasisTIK dapat mengembangkan kemampuan berpikir siswa dan meningkatkan kemampuan guru secara profesional. Guru menjadi lebih termotivasi dan kreatif dalam pembelajaran di kelas. Tujuan dari penelitian ini adalah untuk mengetahui peranan guru dalam menggunakan media pembelajaran berbasis Teknologi Informasi dan Komunikasi di SDN RRI Cisalak. Metodologi dalam penelitian ini adalah deskriptif kualitatif. Dalam penelitian ini dilakukan wawancara mendalam (in deep-interview), pengamatan dan studi kepustakaan. Teknik cuplikannya menggunakan purposive sampling. Teknik analisis data dalam penelitian ini dengan menggunakan langkah-langkah reduksi data, penyajian data, dan penarikan kesimpulan. Hasil penelitian ini adalah guru di SD RRI Cisalak sudah dapat melaksanakan proses pembelajaran dengan menggunakan media pembelajaran berbasis Teknologi Informasi dan Komunikasi. Guru berperan sangat besar dalam kelangsungan pembelajaran berbasis TIK. Peran guru ini didukung pula oleh kepala sekolah dan komite sekolah dalam penunjang sarana dan prasarana dengan memperbanyak media pembelajaran berbasis TIK di sekolah.
\end{abstract}

Kata Kunci: Media Pembelajaran, ICT, Guru

\begin{abstract}
The most important thing in a learning process is the teacher and learning media. Learning media appropriately selected and used by a teacher will certainly have an effect on the learning process and result. The information and Communication Technology (ICT)-based learning media is very important in the development of education. ICT is a program used as a tool for manipulating and conveying information. With ICT, the learning process in the classroom becomes easier because the knowledge and information can be manipulated, manageed and transferred easily. The ICT-based learning media can develop students' thinking skills and professionally improve the ability of teachers. Teachers become more motivated and creative during the class. The purpose of this study is to know the role of teachers in using ITC-based learning media at RRI Cisalak Elementary School. The method used in the research is a qualitative descriptive method. The research conducts in-depth interview, observation and literature review. The samples are taken using a purposive sampling technique. The data are analyzed in some steps, namely data reduction, data presentation, and conclusion. The results of the research show that teachers at SD RRI Cisalak have been able to carry out the learning process by using ICT-based learning media. Teachers play a very big role in the continuity of ICTbased learning. The role of the teacher is also supported by the school principal and school committee by increasing the number of facilities, infrastructures and ICT-based learning media in schools.
\end{abstract}

Keywords: Learning Media, ICT, Teacher 


\section{PENDAHULUAN}

Optimalisasi penyampaian pesan dari seorang guru atau pendidik dalam suatu proses pembelajaran hal yang terpenting adalah metode mengajar dan media pembelajaran kepada siswanya.

Perkembangan ilmu pengetahuan dan teknologi semakin mendorong upayaupaya pembaruan dalam pemanfaatan hasil-hasil teknologi dalam proses belajar. Para guru dituntut agar mampu menggunakan alat-alat yang disediakan oleh sekolah dan tidak menutup kemungkinan alat-alat yang disediakan oleh sekolah sudah sesuai dengan perkembangan dan tuntutan zaman[2].

Pemilihan metode dan media pembelajaran akan menentukan keberhasilan guru dalam proses pembelajaran di kelas. Penggunaan media pembelajaran dapat mempengaruhi motivasi, komunikasi dan interaksi belajar siswa untuk lebih merespon dan interaktif dalam kegiatan pembelajaran di kelas.

Brown menyatakan bahwa pembelajaran adalah penguasaan atau pemerolehan pengetahuan tentang suatu objek atau sebuah keterampilan dengan belajar, pengalaman dan intruksi[3]. Dengan pembelajaran diharapkan guru dapat memberikan informasi dan pengetahuan dengan maksimal agar terjadi perubahan pada diri siswa secara positif. Guru harus dapat menciptakan pembelajaran yang menyenangkan, terampil sehingga siswa memperoleh pengetahuan dengan mudah dan benar.

Media pembelajaran merupakan alat dan teknik yang digunakan sebagai perantara komunikasi antara seorang guru dengan siswa. Media pembelajaran digunakan dalam rangka mengefektifkan komunikasi dan interaksi antara guru dan siswa dalam proses pembelajaran di sekolah [5] Dalam proses pembelajaran harus dapat memberikan pengaruh yang baik kepada siswanya. Hal ini dikarenakan pengalaman yang dialami siswa dengan apa yang disajikan oleh guru dalam proses pembelajaran di kelas akan berpengaruh pada perilaku siswa sesuai yang dipahami. Pemerintah Indonesia melalui Keppres No.6/2001 telah mulai mencanangkan $e$ education. Ini berarti bahwa pemerintah telah melakukan inisiasi pemanfaatan TIK dalam bidang pendidikan.

Sistem pembelajaran adalah suatu kombinasi terorganisasi yang meliputi unsur-unsur manusiawi, material, fasilitas, perlengkapan dan prosedur yang berinteraksi untuk mencapai suatu tujuan[11]. Saat ini ketika ilmu pengetahuan dan teknologi berkembang pesat, siswa dapat belajar dimana saja dan kapan saja. Di sisi lain, guru harus mampu meningkatkan kualitas dalam keterampilan menggunakan berbagai media pembelajaran yang sesuai dengan kemajuan teknologi. Proses pembelajaran pada masa sekarang tidak tergantung pada guru sebagai sumber belajar, tapi siswa pun dapat mencari informasi untuk mendampatkan ilmu dan pengetahuan.

Wijaya Kusumah menyatakan bahwa berkembangnya pengetahuan teknologi informasi dan komunikasi menyebabkan terjadinya perubahan dalam sistem pembelajaran[9]. Berbagai bahan pelajaran yang dapat disajikan melalui buku, film, slide suara, foto, $\mathrm{CD}$ adalah unsur material. Sedangkan perlengkapan komputer, audiovisual adalah unsur fasilitas dan perlengkapan. Hal ini dapat diketahui bahwa dalam pembelajaran juga harus dapat dikombinasikan oleh guru, fasilitasnya dan materialnya agar tujuan pembelajaran di kelas dapat tercapai.

Dalam pembelajaran di era globalisasi saat ini tentunya guru harus dapat mengubah metode ceramah ke media pembelajaran berbasis TIK. Hal ini dikarenakan dengan 
adanya TIK siswa akan mendapatkan informasi yang cepat dan guru dapat mengasah keterampilannya dalam memanfaatkan TIK. Guru harus menjadi pembelajaran lebih menarik dengan menggunakan TIK. Pembelajaran harus menjadi menyenangkandan guru harus dapat membuat inovasi sendiri dalam proses pembelajaran dengan TIK.

SDN RRI Cisalak merupakan sekolah yang memiliki fasilitas dan sarana yang masih minim dalam penggunaan TIK, untuk itu kegiatan penelitian ini akan melihat sejauh mana guru berperan dalam penggunaan media pembelajaran berbasis TIK. Fasilitas dan sarana sekolah juga akan mempengaruhi guru dalam penggunaan TIK. Selain itu, kemampuan guru dalam penggunaan TIK tentunya sangat berperan penting dalam pembelajaran.

\section{METODE}

Metodologi penelitian ini adalah deksriptif kualitatif. Penelitian ini melakukan wawancara, pengamatan dan studi kepustakaan. Teknik analisis data dalam penelitian ini adalah reduksi data, penyajian data dan kesimpulan.

\section{HASIL DAN PEMBAHASAN}

Hasil temuan di SDN RRI Cisalak diketahui bahwa guru memiliki peranan yang penting dalam penggunaan media pembelajaran berbasis TIK. Hal ini dikarenakan guru yang menjadi tonggak utama dalam pelaksanaan pembelajaran di kelas. Pemahaman dan penguasaan guru tentang TIK sudah cukup dapat dipahami oleh guru. Akan tetapi, tidak semua guru beralih dari metode ceramah ke media pembelajaran berbasis TIK hal ini dikarenakan fasilitas dan sarana yang masih belum tercukupi di semua ruang kelas. Selain beberapa guru yang masih kesulitan dalam mengoperasikan komputer, laptop, LCD, audiovisual ataupun browsing internet hal ini tidak menyusutkan semangat para guru untuk menggunakan media pembelajaran berbasis TIK.

Hal ini juga didukung dari pernyataan Wijaya Kusumah yang menyatakan bahwa pembelajaran yang menarik haruslah memfasilitasi siswa untuk berhasil mencapai tujuan pembelajaran secara optimal dengan cara yang mudah, cepat dan menyenangkan [9].

Hasil temuan lain adalah guru-guru di kelas 4,5,6 yang lebih antusias dalam penggunaan media pembelajaran berbasis TIK. Hal ini dikarenakan waktu dan durasi di kelas lebih lama dibanding kelas 1,2,3. Siswa di kelas 4,5,6 pun menjadi lebih termotivasi dan antusias dalam pembelajaran di kelas dengan menggunakan media pembelajaran berbasis TIK. Siswa menjadi semangat dalam belajar, mencari ilmu dan informasi terkait yang disampaikan guru dan berpikir lebih luas. Dalam pengerjaan tugas di luar kelas pun siswa di kelas 4,5,6 sudah mampu menggunakan komputer, laptop atau browsing tugas melalui internet.

Berdasarkan hasil observasi dan wawancara bahwa guru-guru di kelas 1,2,3 kesulitan dalam menggunakan media pembelajaran berbasis TIK hal ini dikarenakan durasi yang sangat singkat di kelas, fasilitas dan sarana yang masih minim di ruang kelas untuk penunjang pembelajaran berbasis TIK, sulitnya mengkondisikan siswa karena masih membutuhkan perhatian yang lebih khusus sehingga guru di kelas 1,2,3 belum semua siap dalam menggunakan media pembelajaran berbasis TIK.

Dari uraian tersebut didukung oleh pernyataan Wijaya Kusumah menyatakan bahwa teknologi yang tepat dilakukan dalam pembelajaran adalah dengan memanfaatkan alat yang dimiliki oleh guru 
atau sekolahnya. Jika yang dimiliki hanya berupa VCD maka guru tersebut dapat memanfaatkan VCD itu menjadi menarik [9]. Sehingga dapat dikatakan bahwa teknologi yang terbaik dalam pembelajaran adalah guru dapat mengoperasikan alat atau benda (hasil teknologi) dengan cermat dan tepat. Jika di sekolah belum menunjang fasilitas seperti laptop, internet, maka tidak menyurutkan guru untuk menggunakan media pembelajaran berbasis TIK. Guru tidak perlu menunggu fasilitas dan sarana yang terpenuhi untuk menggunakan TIK dalam pembelajarannya. Sebab dengan Video, Film, VCD guru pun sudah bisa disebut menggunakan media pembelajaran berbasis TIK.

Media pembelajaran memiliki fungsi sebagai berikut [10] :

1. Fungsi komunikatif

2. Fungsi motivasi

3. Fungsi kebermaknaan

4. Fungsi penyamaan persepsi

5. Fungsi individualitas.

Media pembelajaran tentunya membawa peran seorang guru untuk lebih inovatif dan produktif dalam menyajikan materi yang disampaikan kepada siswa di kelas. Guru harus pandai dalam memilih media pembelajaran yang dapat menjadi motivasi bagi siswa dan komunikatif dalam pembelajaran di kelas.

Menurut kepala sekolah SDN RRI Cisalak, media pembelajaran berbasis TIK sudah sangat dan harus diterapkan di era globalisasi saat ini. Kepala sekolah mengajukan kepada instansi terkait untuk mengadakan penyediaan laptop, jaringan internet, komputer dan LCD untuk penunjang media pembelajaran TIK. Selain itu, kepala sekolah kedepannya mengadakan pelatihan untuk para guru dalam peningkatan kemampuan guru dalam menggunakan media pembelajaran berbasis TIK.

Penggunaan TIK sebagai media pembelajaran tentunya memiliki kontribusi dan inovasi yang besar pada dunia pendidikan. Dengan adanya TIK sangat memberikan kemudahan untuk guru dalam meningkatkan kemampuan mengajarnya. Kreatifitas dan keterampilan guru dapat terlihat dari penggunaan media pembelajaran berbasis TIK. Guru dengan mudah mencari literatur dan informasi terkait dengan materi yang akan disajikan.

Teknologi informasi baik secara implisit maupun eksplisit tidak sekedar berupa teknologi komputer tetapi juga teknologi telekomunikasi. Dengan kata lain teknologi informasi adalah gabungan teknologi komputer dan teknologi telekomunikasi:

1. Teknologi Komputer

Adalah teknologi yang berhubungan dengan komputer seperti printer, CD Room.

2. Teknologi Telekomunikasi Adalah teknologi yang berhubungan dengan komunikasi jarak jauh[1].

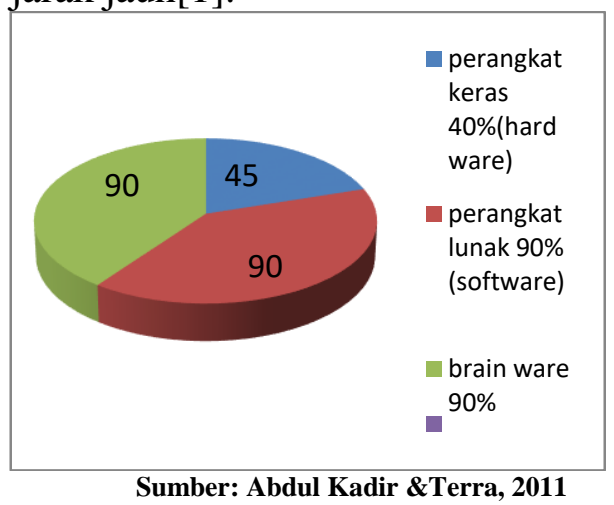

\section{Gambar 1: Tiga Komponen Utama dalam Teknologi Informasi}

Hardware komputer merupakan sekumpulan perangkat keras yang ada dalam komputer, seperti CPU, Input Device, dan Output Device. 
Software adalah seperangkat hardware yang membentuk sebuah PC dan kumpulan beberapa perintah yang dieksekusi oleh mesin komputer dalam menjalankan pekerjaannya.

Brainware adalah perangkat intelektual, dalam hal ini adalah manusia yang mengoperasikan dan mengeksplorasi kemampuan dari software dan hardware[7].

Dari ketiga komponen tersebut dapat diketahui bahwa teknologi informasi dan komunikasi tidak dapat berjalan dengan baik apabila tidak didukung pula oleh kemampuan manusianya dalam mengoperasikan komputer. Hardware tidak dapat bekerja tanpa software. Sedangkan software dan hardware tidak dapat bekerja tanpa brainware atau manusianya.

Teknologi komunikasi adalah teknologi yang berkaitan dengan media pengirim data jarak jauh. Teknologi informasi adalah teknologi yang menggabungkan komputasi dengan jalur komunikasi berkecepatan tinggi yang membawa data, suara dan video [6].

Kajian TIK Menurut Lantip Prosojo antara lain[4]:

\section{E-learning}

2. Manajemen informasi

3. Teknologi informasi

4. Teknologi komputer

5. Sistem informasi manajemen

6. Internet

7. Teknologi telekomunikasi

8. Teknologi jaringan komputer

9. Sistem keamanan jaringan komputer

10. Sistem basis data

Dari kesepuluh kajian TIK menurut Lantif di atas bahwa guru di SDN RRI Cisalak sudah mulai menggunakan teknologi informasi, teknologi komputer dan internet. Meskpiun belum semua guru menggunakan media pembelajaran berbasis TIK dikarenakan kurangnya keterampilan dan penguasaan guru penggunaan TIK dalam pembelajaran di kelas. Hal yang perlu ditingkatkan adalah kreativitas dan keterampilan guru untuk menggunakan TIK dalam pembelajarannya di kelas. Siswa sudah siap menerima TIK dalam pembelajaran di kelas hal ini dapat dilihat dari antusias siswa dalam menyimak dan memahami pembelajaran di kelas yang disampaikan oleh guru.

TIK adalah sebagai alat bantu yang digunakan guru dalam proses pembelajaran di kelas. Suatu alat tidak dapat berfungsi dengan baik jika guru tersebut tidak paham dan mampu secara kreatif untuk menggunakan alat tersebut untuk menjadi menarik dan bermanfaat dalam pembelajaran. Sehingga dibutuhkan keterampilan guru dalam penggunaan TIK agar tujuan pembelajaran tetap tercapai dengan menggunakan TIK.

Media pembelajaran adalah segala sesuatu yang dapat digunakan untuk menyalurkan pesan dan merangsang terjadinya proses belajar pada siswa [12]. TIK merupakan media yang tepat dalam menyampaikan pesan dan merangsang siswa untuk belajar.

Prinsip umum dalam pembuatan media pembelajaran antara lain [12]:
1. Visible
2. Interesting
3. Simple
4. Useful
5. Accurate
6. Legitimate
7. Structured.

Dalam mempersiapkan media pembelajaran tentunya, guru harus mengetahui minat siswa dalam belajar di kelas dengan media pembelajaran yang 
mudah dilihat, menarik, sederhana tetapi bermanfaat bagi siswa. Media pembelajaran berbasis TIK yang melibatkan teks, gambar, suara dan video dapat menyajikan materi pelajaran lebih menarik dan tidak monoton serta mudah dalam penyampaiannya kepada siswa.

\section{SIMPULAN}

Guru di SDN RRI Cisalak memiliki peran yang penting dalam penggunaan media pembelajaran berbasis TIK. Hal ini karena guru yang langsung berinteraksi dengan siswa melakukan proses pembelajaran di kelas. Dengan menggunakan media pembelajaran berbasis TIK tentunya akan meningkatkan kualitas, kreativitas dan profesionalisme guru dalam pengajaran.

Pemahaman media pembelajaran berbasis TIK harus dipahami dan digunakan oleh semua guru di SDN RRI Cisalak karena sudah sangat wajib dilakukan di era globalisasi saat ini meskipun peran guru tidak dapat tergantikan dengan kehadiran TIK. TIK tidak dapat berfungsi dengan baik jika tidak digunakan dengan tepat oleh guru yang terampil.

Dukungan dari pihak dinas terkait, kepala sekolah, komite sekolah dalam pengadaan sarana dan fasilitas yang memadai pembelajaran berbasis TIK sangat dibutuhkan agar tujuan pembelajaran dapat berjalan dengan maksimal ditengah kemajuan teknologi saat ini.

\section{DAFTAR PUSTAKA}

[1] Abdul Kadir dan Terra Ch Triwahyuni, Pengantar Teknologi Informasi Edisi Revisi, Yogyakarta: CV. Andi Offset, 2013.

[2] Azhar Arsyad, Media Pembelajaran, Depok: PT Raja Grafindo, 2013.

[3] Brown, Douglas. Prinsip Pembelajaran dan Pengajaran Bahasa. Terj. Noor
Cholis Yusi Avianto P. Jakarta: Kedutaan Besar AS, 2008.

[4] Diat, Prasojo, Lantif, Teknologi Informasi Pendidikan, Yogyakarta: Gava Media, 2011.

[5] Ega Rima, Ragam Media Pembelajaran, Jakarta: Kata Pena, 2016.

[6] Khairina, Pengenalan Teknologi Informasi dan Teori Pemrograman, Tangerang: Pustaka Mandiri, 2011.

[7] Madcoms, Panduan Lengkap Menjadi Teknisi Komputer, Yogyakarta : Andi Offset, 2014.

[8] Warista, Bambang, Teknologi Pembelajaran: Landasan\& Aplikasinya, Jakarta: Rineka, 2008.

[9] Wijaya Kusumah, Dalam Seminar Nasional Pendidikan Tantangan Menghadapi Era Teknologi Dalam Pendidikan Masa Kini, Aula Gedung PGRI Jakarta, 28 April 2018.

[10]Wina Sanjaya, Media Komunikasi Pembelajaran, Jakarta: Prenada Media Group, 2012.

[11] Wina Sanjaya, Perencanaan \& Desain Sistem Pembelajaran, Jakarta:Prenada Media Group, 2013.

[12]Zainal Aqib, Model-Model Media dan Strategi Pembelajaran Kontekstual Inovatif, Bandung: Yrama Widya, 2017. 